\title{
Prevalence of Neonatal Mortality and Its Associated Factor among Neonates Who Admitted In Neonatal Intensive Care Unit At Debre Tabor General Hospital, South Gondar, Amhara, Ethiopia
}

Solomon kebede Demis ( $\nabla$ solomondemis@gmail.com )

Debre Tabor University https://orcid.org/0000-0003-0537-7571

Tigabu Munye

Debre Tabor University

Biniam Munye

Debre Tabor University

\section{Research}

Keywords: Neonatal Mortality, NICU, Debre Tabor General Hospital, South Gondar

Posted Date: January 19th, 2021

DOl: https://doi.org/10.21203/rs.3.rs-147885/v1

License: (c) (i) This work is licensed under a Creative Commons Attribution 4.0 International License.

Read Full License 


\section{Abstract}

\section{Background}

Neonatal mortality is the death of newborn babies from the time of birth to 28 completed days of life which are the most vulnerable time for a child's survival. About one million of them passed away on their first day of life, and more than two thirds (38\%) of the deaths were in sub-Saharan Africa where Ethiopia is one of the countries with the highest neonatal mortality in the world which accounts for 29 deaths per 1,000 live births.

Objective

To assess the prevalence and associated factors of neonatal mortality among neonates admitted in Debre Tabor General Hospital in South Gondar, Ethiopia.

\section{Methods}

Institutional based retrospective cross-sectional study design was conducted from November 1, 2018, up to January 30, 2019, in Debre Tabor General Hospital. A Structured interviewer-administered pre-tested questionnaire was used to collect data. The collected data were entered into Epi data version 4.2 and then exported into SPSS window version 24. Bivariate and multivariate analysis was undertaken and information was presented by using simple frequency tables, graphs, and pie charts.

Result

the prevalence of neonatal mortality was found to be $12.3 \%$. Gestational age group 28-32 weeks (AOR = 9.5, 95\% Cl: 2.39-37.97), Gestational Age beyond 42 weeks (AOR $=4.6,95 \% \mathrm{Cl}: 6.3-33.8$ ), and forceps delivery (AOR $=0.18,95 \% \mathrm{Cl}: 0.05-0.68)$ were found to be statistically significant.

Conclusion and recommendation

Neonatal mortality was higher than the national with independently associated factors of prematurity and post maturity while forceps delivery as a preventive factor. Therefore, this might be essential to the hospital NICU to plan for managing prematurity and post maturity in better quality as well as providing quality ANC and identifying most predisposing factors for prematurity.

\section{Introduction}

Neonatal morbidity and mortality are the major global public health challenges, specifically for the first 28 days of life. Globally, each year over 4 million neonates died within 28 days of birth among 130 million births. Every minute, twenty under-five children die, leading to 8 million deaths before they reach their fifth birthday due to the conditions which could be either avoided or treated. Neonatal mortality accounts for two- thirds of deaths of infants, and nearly two-fifths of all deaths in under-five children. Many babies die 
nameless and unrecorded, indicating the perceived inevitability of their deaths. Most neonatal deaths (99\%) occur in low and middle-income countries, where about half of the deaths occur at home [2].

Ethiopia, one of the countries with the highest neonatal mortality in the world, is responsible for 29 deaths per 1,000 live births which was over 9 times more than that of highly developed countries, where the rate is 29 per 1,000 live births [1].

The health of future societies depends on the health of the children of today and their mothers. The neonatal period is considered as the highest risk period. Childhood mortality is often used as a broad indicator of social development or a specific indicator of the health conditions of a country. However, child health programs were given low attention, especially neonatal health [5].

Every year an estimated 4 million babies die in the first 4 weeks of life (the neonatal period). Threequarters of neonatal death happens in the first week, the highest risk of death is on the first day of life. The highest number of neonatal death was in South Asian countries and the highest rate is generally in sub-Saharan Africa. Preventing death in newborn babies has not been a focus of child survival or safe motherhood programs. While we neglect these challenges, 450 newborn die every hour, mainly from the preventable cause which is unjustifiable in the 21 century [2].

Neonatal mortality accounts for $44 \%$ of under-five mortality in 2014. Average death during the neonatal period is 30 times higher compared to the rest of under-five children.

Ten countries account for $67 \%$ of neonatal mortality globally by which Ethiopia accounts for $4 \%$ of global neonatal mortality [6].

Neonatal mortality has three main causes in low and middle-income countries. The complication of preterm, asphyxia, and neonatal infection together contribute to $85 \%$ of newborn death.

In $2013,35 \%$ of the global neonatal deaths were caused by complications of preterm birth, $24 \%$ by intrapartum related complications, and $25 \%$ by infection. The rest of the death is caused by congenital malformations $[7,8]$.

In Ethiopia, the rate of under-five mortality (U5MR) decreased by 60\% from the year 2000 to 2016 which implies from 123 to 67 per 1000 of live births. However, the neonatal mortality rate (NMR) decreased only by $40 \%$ from $49 / 1000$ live births to 29 per 1000 live births from 2000 to 2016 . Because of this, the share of neonatal mortality in under-five mortality has been increased from $29.5 \%$ to $43 \%$ [3].

Neonatal health problems are usually seen as similar to an older child's health problem. But, the causes of neonatal mortality and intervention to improve neonatal health are different from that of other underfive children. Neonatal survival is the most important indicator of improved health care during childbirth. There is a gap in integrating the need for care of neonates in the NICU, the neonatal health problems, and health programs for maternal and child health. As a result, there is still slow progress to decrease 
neonatal mortality in the majority part of the country by which they contribute to the national burden of neonatal mortality in Ethiopia.

Even though there were some endeavors in identifying major causes of neonatal death, in Ethiopia, studies that identify the prevalence and associated factors of neonatal mortality were limited specifically for hospital admitted neonates. Having data on the prevalence of the problem is crucial to take prioritized actions. Therefore, this study has done to identify the prevalence of neonatal mortality and associated factors among NICU admitted neonates.

\section{Methods}

\section{Study Design and period}

An Institutional based cross-sectional study was conducted from November 1, 2018, to January 30, 2019, in Debre Tabor General Hospital in NICU among admitted neonates.

\section{Study setting}

Debre Tabor General Hospital is found in the South Gondar zone in the Amhara region of Ethiopia. It was officially commenced its function in 1917 and currently, it delivers the health care services for more than 2.3 million populations through medical, surgical, gynecological, pediatrics, NICU, ophthalmological wards, and 14 OPD with a total of 182 beds and 444 staffs.

Annually, nearly more than 1250 neonates were admitted to the neonatal intensive care unit with different health problems. It has 22 beds, 3 pediatricians, and 20 nurses in which 2 are neonatal nurses.

\section{Study population}

All neonates who were admitted at NICU in Debre Tabor General Hospital from November 1, 2018, up to January 30, 2019.

\section{Sample size estimation}

The sample size was calculated using single population proportion formula and by taking into the following consideration: prevalence $(P)$ of neonatal mortality $13.29 \%$ [17] confidence level (CL) $95 \%$, the margin of error (d) 5\%, and by adding 10\% for non-response rate. The final sample size came up to 195 . However, to make a statistical analysis of logistic binary logistic regression, a $50 \%$ proportion (p) was used to get the final sample size to be 422 .

\section{Data collection and procedure}

Before data collection, both the data collectors and supervisors have trained by the principal investigator for one day. Secondary data was collected from Neonatal ICU treatment registers by using a structured questionnaire and checklist designed in the way that it could collect pieces of information about all the 
relevant variables. Then it was pre-tested with individuals equivalent to $5 \%$ of the calculated sample size among Debre tabor General hospital. Data were collected by two Bsc nurses and one Msc nurse for the supervisor. The data has collected among admitted neonates on a specified period from NICU. A simple random sampling method was used to select neonates admitted in NICU from medical records. This was done by sampling frame 1 up to $N[1 ; 1000]$ admitted neonates in NICU, then choose 422 samples were chosen every 2 intervals of medical record systematically, so it was taken the sample from a patient chart and register which have full information.

\section{Data quality control}

Data quality was assured by proper designing of the questionnaire in Amharic the local language to prevent misinterpretation, apply pre-test on $5 \%$ of the sample in Debre Tabor General Hospital. The data have also coded, entered, cleaned, and made close supervision during data collection by the principal investigator.

\section{Data analysis}

Then data have coded, entered, and cleaned using Epi-data version 4.2 software and finally exported into SPSS version 24 for analysis. Bivariate analysis, crude odds ratio with $95 \% \mathrm{Cl}$, was used to see the association between each Independent variable and the outcome variable by using binary logistic regression. Independent Variables with a p-value of $\leq 0.05$ were included in the multivariable analysis to control Confounding factors. Adjusted odds ratios with $95 \% \mathrm{Cl}$ were estimated to identify the prevalence and associated factors of neonatal mortality using multivariable logistic regression analysis. The level of statistical significance was declared at $p$-value $\leq 0.05$.

\section{Ethical consideration}

Ethical clearance was obtained from Debre Tabor University, college of health sciences, Institutional Health Research Ethics Review Committee (IHRERC). A formal letter for permission and support was written from Debre Tabor University to Debre Tabor General Hospital. Finally, informed consent was obtained from NICU coordinators.

\section{Results}

\section{Sociodemographic characteristics}

From a total of 928 selected neonatal charts during study periods, 422 neonatal charts were reviewed. The majority of the maternal age group were 20-34 and the least were age group 20 and below which accounts $284(67.3 \%)$ and $16(3.7 \%)$ respectively. The majority 392 (92.90\%) were born from married parents while 219 (51.8\%) were from rural family while 203 (48.2\%) from urban; and 172 (40.5\%) born from mothers with no formal education and $41(9.7 \%)$ were from mothers with completed primary educational level. The majority of neonates were from housewife mothers and the least was from other occupations which account for $223(52.8 \%)$ and 80 (19\%) respectively (Table 1). 


\section{Prevalence of neonatal mortality}

The prevalence of neonatal mortality was found to be $12.3 \%$ (figure 1 ).

\section{Neonatal Characteristics}

Out of 422 neonates, female, male, and ambiguous genitalia were 214 (50.7\%), 207 (49\%), and 1(0.3\%) respectively. The majority of neonates were admitted at age less than or equal to 7 days 409 (96.92\%) and the least $13(3.08 \%)$ was 8 days or beyond.

Most neonates died at early neonatal age and late neonatal age which accounts for 45 (87\%) and 7(13) respectively. Sepsis 203 (48.2\%), asphyxia 95 (22.56\%), and others 71 (16.92\%) were the leading cause of neonatal admission from first to third respectively whereas the majority 209 (53.85\%) were low birth weight and the least were very low birth weight which accounts $10(2.56 \%)$. The majority of neonates were born from mothers whose membrane rupture from 1 to 12 hours $395(93.58 \%)$ and those with 12 to 24 hours duration were $26(6.15 \%)$.

\section{Pregnancy and obstetric characteristics}

The majority of maternal factors were duration of labor lasts from one to twelve hours 218 (56.41\%), and the least was above twenty-four hours 19 (5.13\%). Regarding labor delivery, the majority were through SVD, and least were forceps which accounts for 296 (70.26\%) and 33 (7.69\%) respectively.

The majority were delivered at health institution 389 (92.28 \%) and the majority of presentations were cephalic which accounts for 315 (81.03\%). The majority of neonates were term (37-42 weeks) 232 (54.80\%) and the least were both post-term ( $\geq 42$ weeks) and unknown gestational age which accounts for 13 (3.10\%). The majority 385 (91.28\%) had ANC follow up visits whereas $37(8.72 \%)$ did not have ANC follow up in which majority 192 (45.64\%) had four ANC visits (Table 2).

\section{Maternal health problems during pregnancy}

The majority, 303 (71.9\%) women did not have health problems during pregnancy while the rest 119 (28.2\%) had different health problems at the latest pregnancy (Figure 2).

\section{Types of health problem during pregnancy}

Among 119 women who had a health problem, 86 (72.27\%) were with hypertensive disorders during pregnancy and those with other disorders were 2 (1.68\%) (Figure 3).

\section{Factors associated with neonatal mortality}

Binary and multiple logistic regression has been used to identify associated factors. There was no marked variation by mode of delivery, presentation of labor, maternal health problems during pregnancy, 
and maternal educational level even though it appeared associated factors of neonatal mortality by bivariate analysis.

Neonatal gestational age group (28-32 weeks) and beyond 42 weeks were risk factors for neonatal mortality while forceps delivery was a protective factor for neonatal mortality.

Neonates with (28-32 weeks) age group were 9.5 times more likely to die than (37-42 weeks) age group. And those with gestational age group $>42$ weeks were 4.6 times more likely to die than the gestational age group (37-42 weeks). Those neonates who delivered by forceps were $18 \%$ less likely to die than SVD (Table 3).

\section{Discussion}

In this study, the prevalence of neonatal mortality was $12.3 \%$. The prevalence was higher than the national neonatal mortality with is 29 per 1000 live births (1). The study conducted at Jimma specialized hospital and Felege Hiwot Referral Hospital Ethiopia showed that neonatal mortality was $35.4 \%$ which was nearly three times higher than the prevalence in Debre Tabor Hospital and $13.29 \%$ which was comparable to this study respectively $(14,17)$. And this study finding was higher than the study conducted in Dire Dawa Ethiopia which was $11.44 \%$ (20). The study conducted in Pakistan showed that neonatal mortality was $27 \%$ which was higher than this study (10).

This variation might be due to the different socioeconomic status of the mother and the level of differences among hospitals in which the studies conducted.

The previous studies showed that mode of delivery, educational status of secondary school, marital status, household wealth, male sex and ANC visit, preterm gestational age, and early neonatal age were associated factors for neonatal mortality $(17,18)$. Similarly, in this study, forceps delivery and gestational age group (28-32 weeks) had a significant association for neonatal mortality. Besides, the gestational age group beyond 42 weeks was associated factors

The neonate who was delivered through forceps were $18 \%$ less likely to die than those who delivered by spontaneous vaginal delivery. But, the study in Sudan showed that neonates delivered in $\mathrm{C} / \mathrm{S}$ were more likely to die than spontaneous vaginal delivery (11). This might be due to the timely management of labor which in turn decreases labor complications.

Gestational age at delivery was significantly associated with neonatal mortality. The preterm newborns (28-32) weeks were 9.5 times more likely to die than those who were delivered at term (37-42) weeks which was 4 times higher than the study conducted at Bahir Dar Felege Hiwot Referral Hospital (17). This might be due to differences in hospital care levels like ANC, institutional delivery, and quality of maternal health service.

\section{Limitation}


Secondary data was used that makes it difficult to collect full data from registration and charts due to missing of some treatment outcomes and other relevant data.

\section{Conclusion And Recommendation}

The prevalence of neonatal mortality was higher compared to the national figure while Factors associated with neonatal mortality were prematurity (28-32 weeks) of gestational age, post-term ( $>42$ weeks) of gestational age, and preventive forceps delivery. And, the way forwarded, using this stud as input would be providing client-based individualized ANC care to decrease prematurity, enhanced pre term care at NICU, and studies on causes of prematurity as it was the leading factor for neonatal mortality in this study.

\section{References}

1. WHO, U. and C. Mathers, Global strategy for women's, children's and adolescents' health (2016-2030). The organization, 2017. 2016(9).

2. Lawn, J.E., et al., 4 million neonatal deaths: when? Where? Why? Lancet, 2005. 365(9462): p. 891900.

3. Tarekegn, S.M., L.S. Lieberman, and V. Giedraitis, Determinants of maternal health service utilization in Ethiopia: analysis of the 2011 Ethiopian Demographic and Health Survey. BMC pregnancy and childbirth, 2014. 14(1): p. 161.

4. Antonucci, R., A. Porcella, and M.D. Pilloni, Perinatal asphyxia in the term newborn. Journal of Pediatric and Neonatal Individualized Medicine (JPNIM), 2014. 3(2): p. e030269.

5. Van Lerberghe, W., The World Health Report 2005: Make every mother and child count. 2005: World Health Organization.

6. Lawn, J.E., et al., Every Newborn: progress, priorities, and potential beyond survival. The Lancet, 2014. 384(9938): p. 189-205.

7. Wang, H., et al., Global, regional, and national levels of neonatal, infant, and under-5 mortality during 1990-2013: a systematic analysis for the Global Burden of Disease Study 2013. The Lancet, 2014. 384(9947): p. 957-979.

8. Bhutta, Z.A., et al., Can available interventions end preventable deaths in mothers, newborn babies, and stillbirths, and at what cost? The Lancet, 2014. 384(9940): p. 347-370.

9. Tran, H.T., et al., A systematic review of the burden of neonatal mortality and morbidity in the ASEAN Region. WHO South-East Asia journal of public health, 2012. 1(3): p. 239.

10. Ayaz, A. and S. Saleem, Neonatal mortality and prevalence of practices for newborn care in a squatter settlement of Karachi, Pakistan: a cross-sectional study. PLoS One, 2010. 5(11): p. e13783.

11. Bashir, A.O., et al., Neonatal mortality in Sudan: analysis of the Sudan household survey, 2010. BMC Public Health, 2013. 13(1): p. 287. 
12. Gizaw, M., M. Molla, and W. Mekonnen, Trends and risk factors for neonatal mortality in Butajira District, South Central Ethiopia,(1987-2008): a prospective cohort study. BMC pregnancy and childbirth, 2014. 14(1): p. 64.

13. Yaya, Y., et al., Maternal and neonatal mortality in south-west Ethiopia: Estimates and socioeconomic inequality. PloS one, 2014. 9(4): p. e96294.

14. Debelew, G.T., M.F. Afework, and A.W. Yalew, Determinants and causes of neonatal mortality in Jimma zone, southwest Ethiopia: a multilevel analysis of prospective follow up study. PLoS One, 2014. 9(9): p. e107184.

15. Yirgu, R., et al., Perinatal mortality magnitude, determinants and causes in west Gojam: a populationbased nested case-control study. PloS one, 2016. 11(7): p. e0159390.

16. Kolola, T., et al., Determinants of Neonatal Mortality in North Shoa Zone, Amhara Regional State, Ethiopia. PloS one, 2016. 11(10): p. e0164472.

17. Tewabe, T., et al., Neonatal mortality in the case of Felege Hiwot referral hospital, Bahir Dar, Amhara Regional State, North West Ethiopia 2016: a one-year retrospective chart review. Italian journal of pediatrics, 2018. 44(1): p. 57

18. Yared Mekonnen, Biruk Tensou, Daniel S Telake, Ted babe Degefie and Abeba Bekele Neonatal mortality in Ethiopia: trends and determinants JSI Research \& Training Institute, Inc 2013, 13:483. Page 5 of 14

19. Mekonnen al. BMC Public Health Bekele, Neonatal mortality in Ethiopia: trends and Determinants http://www.biomedcentral.com/1471-2458/13/4832013, 13:483 P. 6 of 14.

20. Roba AA and Diro DH. Morbidities, Rate, and Time Trends of Neonatal Mortality in Dilchora Referral Hospital, Dire Dawa, Ethiopia, 2012-2017. Austin Med Sci. 2017; 2(2): 1019.

\section{Tables}

Table 1. Maternal sociodemographic characteristics of prevalence and associated factors of neonatal mortality among admitted neonates in NICU, Debre Tabor Hospital, 2019. 


\begin{tabular}{|c|c|c|c|}
\hline Characteristics & & Frequency & Percentage (\%) \\
\hline \multirow[t]{3}{*}{ Age of mothers } & $<20$ years & 16 & 3.7 \\
\hline & 20-34 years & 284 & 67.3 \\
\hline & $>=35$ years & 122 & 28.9 \\
\hline \multirow[t]{3}{*}{ Marital status } & Married & 392 & $92.90 \%$ \\
\hline & Not married & 28 & $6.63 \%$ \\
\hline & Others & 2 & 0.47 \\
\hline \multirow[t]{2}{*}{ Residence } & Rural & 219 & $51.8 \%$ \\
\hline & Urban & 203 & $48.2 \%$ \\
\hline \multirow[t]{5}{*}{ Educational status } & No formal education & 172 & $40.5 \%$ \\
\hline & Can read and write & 91 & $21.6 \%$ \\
\hline & Primary school & 41 & $9.7 \%$ \\
\hline & Secondary school & 56 & $13.3 \%$ \\
\hline & College and above & 63 & $14.9 \%$ \\
\hline \multirow[t]{3}{*}{ Occupation } & House wife & 223 & $52.8 \%$ \\
\hline & Employers & 119 & $28.2 \%$ \\
\hline & Others & 80 & $19.0 \%$ \\
\hline
\end{tabular}

Table 2. Maternal and neonatal characteristics for prevalence and associated factors of neonatal mortality among admitted neonates in NICU, Debre Tabor General Hospital, 2019. 


\begin{tabular}{|c|c|c|}
\hline Variables & & \\
\hline Cause of admission & Frequency $(n=422)$ & Percent (\%) \\
\hline Asphyxia & 95 & 22.56 \\
\hline Sepsis & 203 & 48.20 \\
\hline Jaundice & 20 & 4.62 \\
\hline Pneumonia & 20 & 4.62 \\
\hline Birth trauma & 13 & 3.08 \\
\hline Others & 71 & 16.92 \\
\hline Duration of labor(DOL) & $N=385$ & Percent \\
\hline $1-12$ hours & 218 & 56.41 \\
\hline 12-24 hours & 148 & 38.46 \\
\hline Above 24 hours & 19 & 5.13 \\
\hline Mode of delivery & $\mathrm{N}=422$ & Percent (\%) \\
\hline SVD & 296 & 70.26 \\
\hline Forceps & 33 & 7.69 \\
\hline Vacuum & 39 & 9.23 \\
\hline $\mathrm{C} / \mathrm{S}$ & 54 & 12.82 \\
\hline Presentation at labor & $N=389$ & Percent (\%) \\
\hline Cephalic & 315 & 81.03 \\
\hline Breach & 66 & 16.92 \\
\hline Others & 8 & 2.06 \\
\hline Gestational age at birth & $N=389$ & Percent (\%) \\
\hline 28-32 weeks & 45 & 10.80 \\
\hline 32-36 weeks & 119 & 28.20 \\
\hline 37-42 weeks & 232 & 54.80 \\
\hline Above 42 weeks & 13 & 3.10 \\
\hline Unknown & 13 & 3.10 \\
\hline Birth weight & $N=386$ & Percent (\%) \\
\hline VLBW & 10 & 2.56 \\
\hline
\end{tabular}




\begin{tabular}{|lll|}
\hline LBW & 209 & 53.85 \\
\hline ANC & 167 & 43.59 \\
\hline Yes & $\mathbf{N}=\mathbf{4 2 2}$ & Percent (\%) \\
\hline No & 385 & 91.28 \\
\hline Duration of rupture of membrane (ROM) & $\mathbf{N}=\mathbf{3 8 9}$ & 8.72 \\
\hline$\leq 12$ hours & 365 & Percent (\%) \\
\hline$>12$ hours & 24 & 93.84 \\
\hline
\end{tabular}

Table 3. The factors for prevalence and associated factors among admitted neonates in NICU, Debre Tabor General Hospital (n=422), 2019. 


\begin{tabular}{|c|c|c|c|c|}
\hline \multirow{2}{*}{$\begin{array}{l}\text { Variables } \\
\text { Mode of delivery }\end{array}$} & \multicolumn{2}{|c|}{ Outcome of admission } & \multicolumn{2}{|c|}{ 95\% confidence interval } \\
\hline & Discharged & Died & COR & AOR \\
\hline SVD & 388 (92\%) & $34(8 \%)$ & 1 & 1 \\
\hline Forceps & $\begin{array}{l}366 \\
(86.7 \%)\end{array}$ & $56(13.3 \%)$ & $1.76(0.35-8.82)$ & $0.18(0.05-0.68)^{\star}$ \\
\hline Vacuum & $\begin{array}{l}304 \\
(72.2 \%)\end{array}$ & $\begin{array}{l}118 \\
(27.8 \%)\end{array}$ & $4.40(1.32-14.64)$ & $0.44(0.07-2.82)$ \\
\hline $\mathrm{C} / \mathrm{S}$ & $321(76 \%)$ & $101(24 \%)$ & $3.61(1.19-10.92)$ & $1.49(0.41-7.86)$ \\
\hline \multicolumn{5}{|l|}{ Presentation at labor ${ }^{\mathrm{a}}$} \\
\hline Cephalic & $352(90.5 \%)$ & $37(9.5 \%)$ & 1 & 1 \\
\hline Breach & $295(75.8 \%)$ & $94(24.2 \%)$ & $3.05(1.17-7.94)$ & $0.15(0.0-4.61)$ \\
\hline \multicolumn{5}{|l|}{ Gestational age at birth } \\
\hline $28-32$ wks & $276(71.4 \%)$ & $96(24.8 \%)$ & $3.88(1.23-12.24)$ & $9.5(2.39-37.97)^{*}$ \\
\hline $32-36$ wks & $350(90.2 \%)$ & $38(9.8 \%)$ & $1.05(0.36-3.06)$ & $2.0(0.60-6.7)$ \\
\hline Above 42 wks & $259(66.7 \%)$ & $128(33.3 \%)$ & 4.85(0.78-29.87) & $4.6(6.3-33.8)$ \\
\hline $37-42$ wks & $353(90.7 \%)$ & $35(9.3 \%)$ & 1 & 1 \\
\hline \multicolumn{5}{|c|}{ Problem during pregnancy ${ }^{a}$} \\
\hline Yes & $338(80.8 \%)$ & $84(20 \%)$ & $2.44(1.02-5.84)$ & $2.41(0.72-7.92)$ \\
\hline No & $380(90.7 \%)$ & $38(9.3 \%)$ & 1 & 1 \\
\hline \multicolumn{5}{|c|}{$\begin{array}{l}\text { Educational status of mothers } \\
\text { a }\end{array}$} \\
\hline No formal education & $375(88.9 \%)$ & $42(10.1 \%)$ & $0.43(1.3-1.37)$ & $0.17(0.07-1.55)$ \\
\hline Can read and write & $338(81 \%)$ & $80(19 \%)$ & $0.90(0.27-2.94)$ & $0.99(0.19-5.0)$ \\
\hline Primary school & $397(94.7 \%)$ & $21(5.3 \%)$ & $0.21(0.23-1.93)$ & $0.58(0.03-8.62)$ \\
\hline Secondary school & $405(96.2 \%)$ & $16(3.8 \%)$ & $0.15(0.01-1.37)$ & $0.16(0.01-2.27)$ \\
\hline Above secondary & $333(79.3 \%)$ & $87(20.7 \%)$ & 1 & 1 \\
\hline
\end{tabular}

Note: ${ }^{a}$ variables significant at $p<0.2$ in bi variable analysis, ${ }^{*}$ significant with $p \leq 0.001,1=$ reference.

\section{Figures}




\section{Prevalence of neonatal mortality}

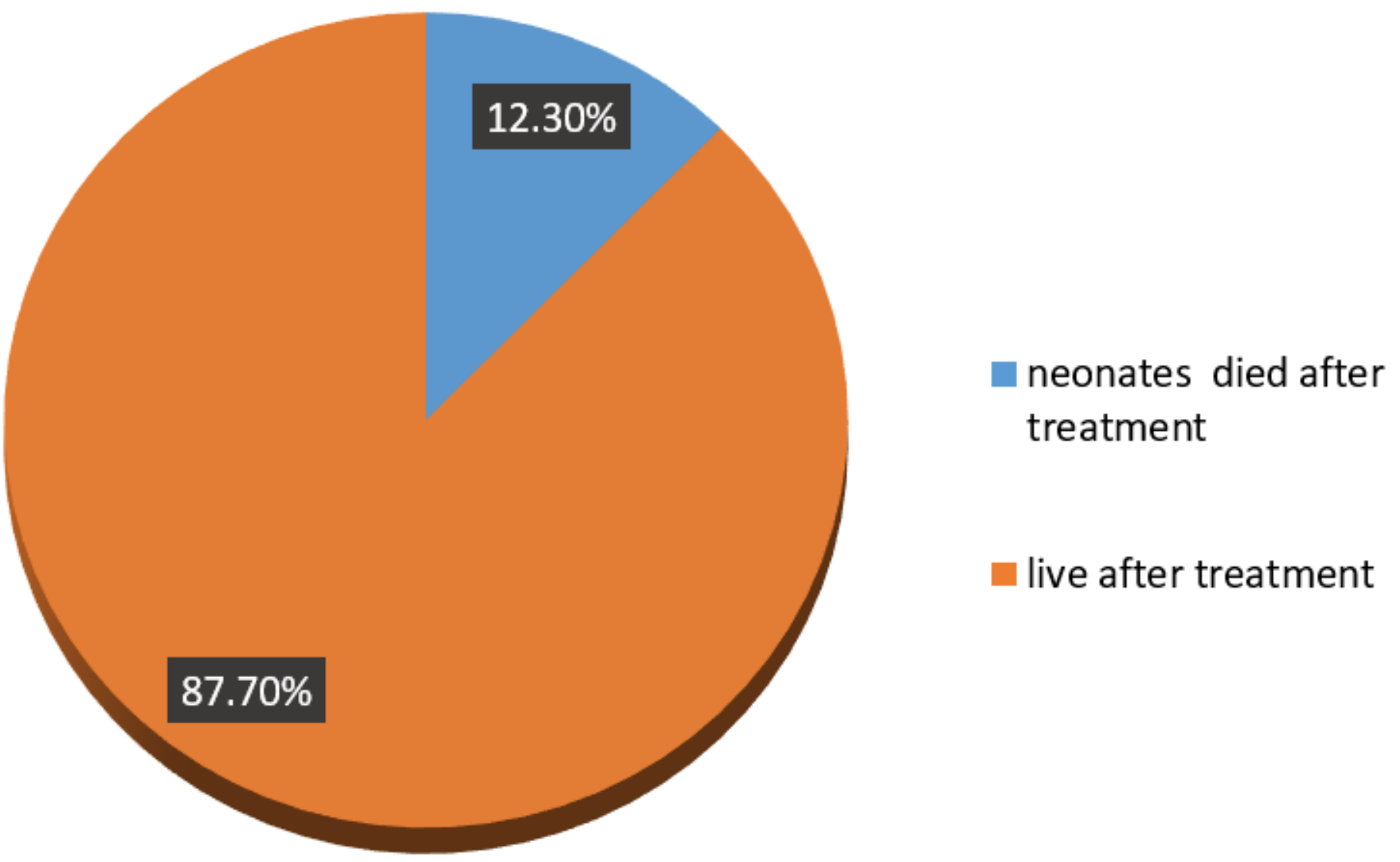

Figure 1

Prevalence of neonatal mortality in NICU, Debre Tabor General Hospital, 2019. 


\section{Health problem}

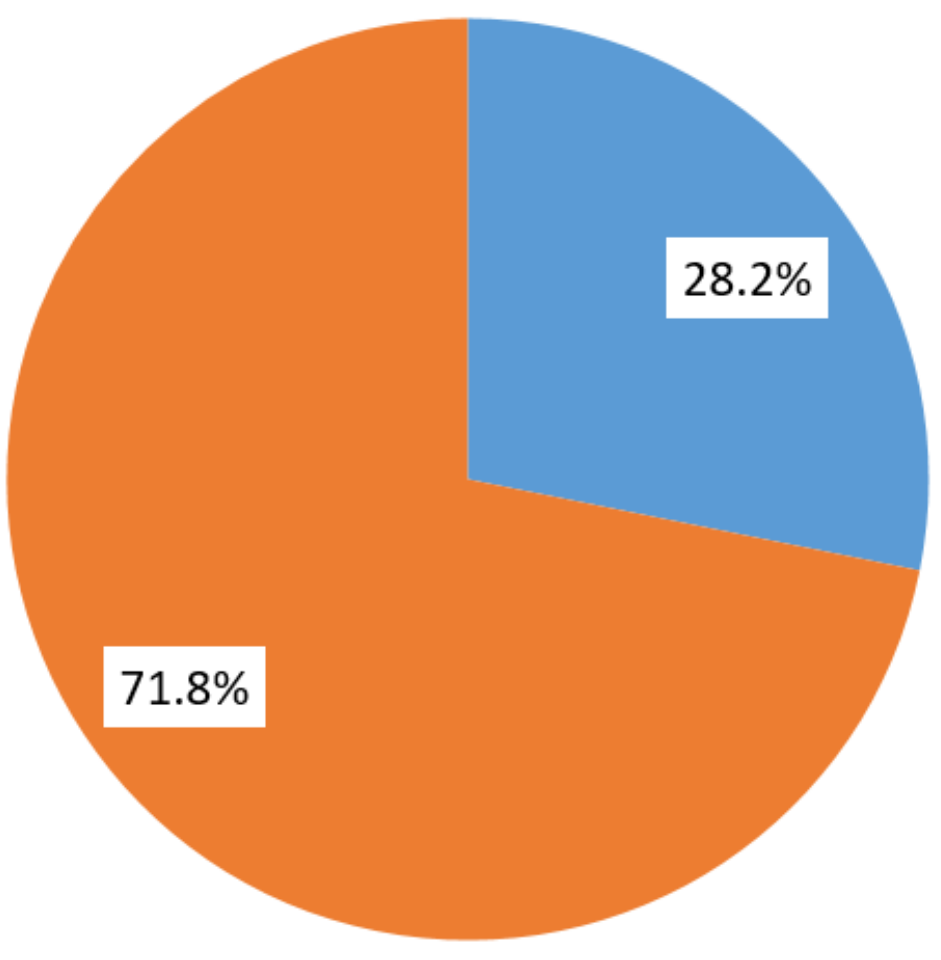

health problem during pregnancy

did not have health problem

Figure 2

Maternal health problems during pregnancy of prevalence and associated factors of neonatal mortality among admitted neonates in NICU, Debre Tabor General Hospital, 2019. 


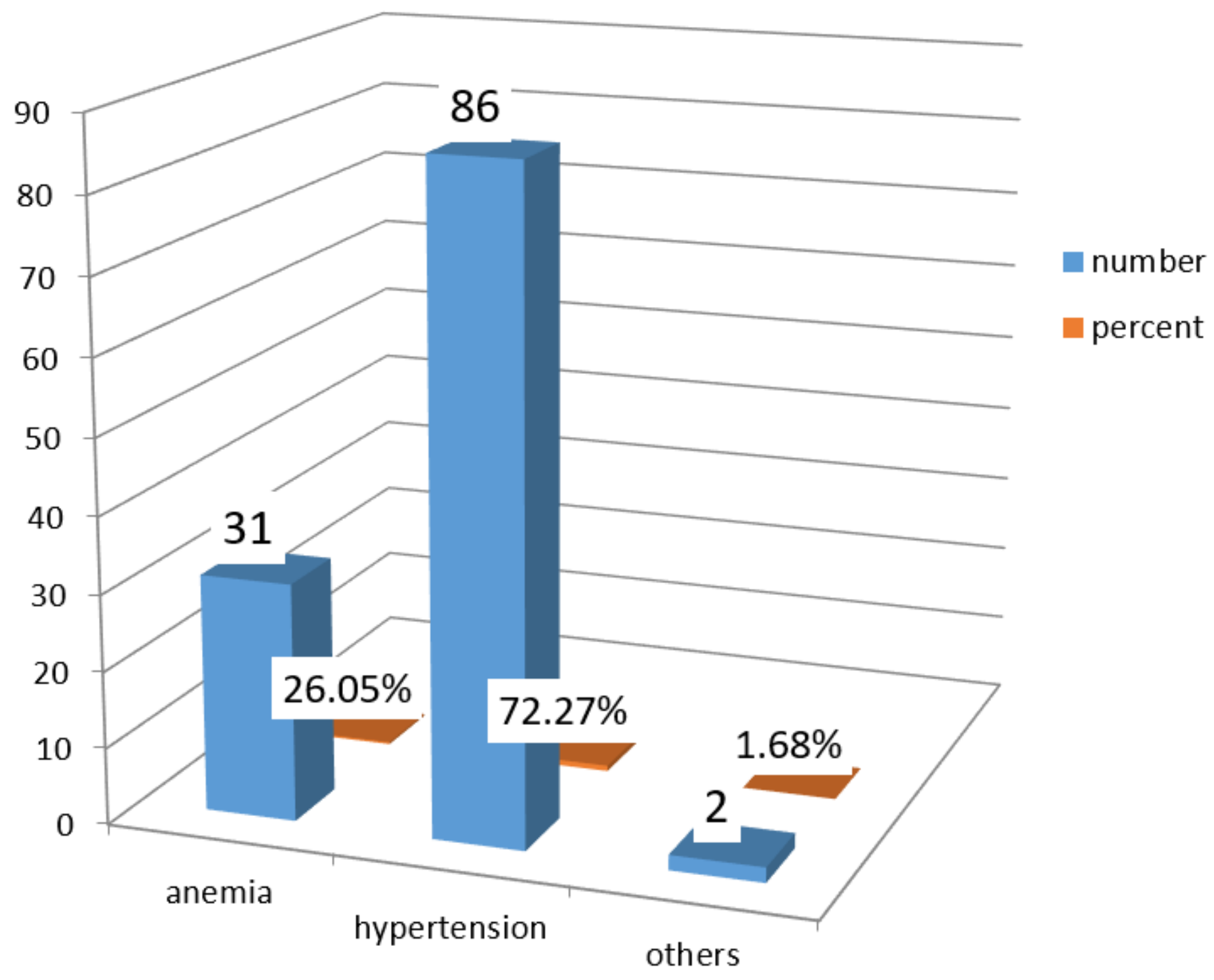

Figure 3

Types of maternal pregnancy health problems of prevalence and associated factors of neonatal mortality among admitted neonates in NICU, Debre Tabor General Hospital, 2019. 